\section{Fly in the face of reason}

Gerald M. Rubin

The Making of a Fly: The Genetics of Animal Design. By Peter A. Lawrence. Blackwell Scientific: 1992. Pp. 228. £16.95, \$29.95 (pbk).

MANY general lessons of developmental biology and pattern formation have emerged from studies of the fruitfly Drosophila in the past decade. Fundamental molecular mechanisms are now understood, at least in broad outline. For example, the way in which simple gradients divide the fruitfly embryo into a series of stripes, each only a few cells wide, can now be discussed in terms of the interactions of identified protein molecules and the sites on DNA to which these molecules bind. Our understanding of these processes is arguably one of the great scientific achievements of the twentieth century.

In The Making of a Fly, Peter Lawrence attempts to convey the excitement of the field, as well as its history. It is a landmark book in that it is the first and only attempt to bring all this information together in one volume and in a form accessible to students. I would recommend it for any graduate student, postdoctoral researcher or professor in the fields of development, cell biology or genetics - it is pitched at the perfect level for me. Although too difficult for use in an undergraduate course in the United States, the book would be a good choice for first year graduate students,

\section{New Journals issue}

This year, Nature's annual New Journals review supplement will appear in the issue of 1 October. Publishers and learned societies are invited to submit journals for review, taking note of the following criteria:

- Journals that first appeared during or after June 1990 and issued at least four separate numbers by the end of April 1992 will be considered.

Journals covering any aspect of science are eligible, although those dealing with clinical medicine, engineering and pure mathematics are excluded, as are publications of abstracts. - Frequency of publication must be at least three times a year. The main language used must be English. Translation journals in English are, of course, eligible.

Deadline for submission is the end of May.

When submitting journals for review, please send at least four different issues (the first, the most recent and any two others) of each title, together with full details of subscription rates (personal and institutional) and frequency of publication, to: Peter Tallack, Nature, 4 Little Essex Street, London WC2R 3LF, UK. For further information please telephone Peter Tallack on $071-836-6633$ (011-44-71-836-6633 from the United States), extension 2414. particularly if it were supplemented with original papers.

Lawrence says in his preface: "The sum of useful information on Drosophila would not fit into a hundred books of this size." This is almost certainly true. Perhaps this book would have been more accessible to a larger audience if it had left more to the other 99. This would have made it more analogous to Mark Ptashne's book A Genetic Switch, on which it was supposedly modelled. Lawrence could have conveyed a few of the basic concepts more clearly by focusing on one or two examples, say the dividing of the embryo into segments. Instead, he plumped for a more inclusive treatment. The result is a book with too many facts, too many moving parts, too much detail on too many subjects. One is reminded of Ambrose Bierce's trenchant observation: "The covers of this book are too far apart." It is not so much that the covers are too far apart, as that the material between them is too densely packed for an undergraduate text. Leavening is provided by such gratuitous details as a description of Sydney Brenner's eyebrows (page 92, so you don't have to hunt). But for graduate students and researchers interested in developmental biology, the book contains much thought-provoking material and provides a superb way to become exposed to a vast body of information.

Lawrence's views of experimental approaches and the intellectual history of the field keep the book from becoming too dry. He is well suited to the task of writing the book, for he brings a unique and refreshingly broad perspective to the field. He is perceptive, critical and opinionated, although opinion and fact are clearly distinguishable throughout. He writes well. One may disagree with him at times, but his ideas are always well thought out.

The book ends with a series of historical anecdotes. These are highly entertaining and serve well to convey both the excitement of the field and the ways in which ideas develop and mature. The many illustrations are clear and of excellent quality. The book is nicely organized and visually very pleasing. The production is superb.

Lawrence has taken on the extremely difficult, perhaps impossible, task of describing an immense body of information in a simple, concise and comprehensible way. Given the complexity of the task, he has achieved a great measure of success. The Making of a Fly fills a huge void and will be sure to inspire a generation of developmental biologists.

Gerald M. Rubin is in the Department of Molecular and Cell Biology, Division of Genetics, University of California, Berkeley, California 94720.

\section{Texan flying mammals}

\section{A. M. Hutson}

The Bats of Texas. By David J. Schmidly. Texas A \& M University Press: 1991. Pp. 188. $\$ 34.50$ (hbk), $\$ 19.95$ (pbk).

TEXAs is the home state of Dr Charles Campbell, whose efforts to demonstrate the value of bats in insect control led to one of the earliest pieces of legislation protecting bats, and the largest bat colonies in the world. In North America, where bats hold a largely misplaced high profile in discussions on rabies, public enthusiasm for these mammals has perhaps been slow to develop. The Bats of Texas appears when interest is definitely on the increase; it aims to further this trend and to provide a better understanding of the role of bats in the biological community and the need for their conservation. A general introduction with special reference to the Texan fauna offers that background.

With 32 species in four families, the Texas bat fauna is the most diverse in North America. The fauna includes 29 insectivorous species, two nectarivorous and - recorded only once - the rarer vampire bats. Illustrated keys to these species are given for external characters and skulls. The core of the book consists of accounts of each species, including a brief description and notes on distribution, subspecies, life history, specimens examined and references. A bibliography of 428 references is included. Each species is illustrated with a good-quality black-and-white photograph and county distribution maps (half the species are also shown in colour). The distribution of species is often related to the ecological zones identified within the state, but unfortunately there is little about the special features of the Texan fauna, such as the influence of the nearby tropics and the meeting in Texas of a large proportion of the world's species of the hairy-tailed bats Lasiurus.

This is a good and thoroughly researched regional guide. The keys seem simple to use (perhaps too simple for the more difficult genus of the mouse-eared bats Myotis) and the species accounts are concise (if sometimes rather overwhelmed by the list of specimens examined). It will certainly appeal to the amateur and professional mammalogist and to many others interested in faunistics and conservation, but it may not open the gate to the wider public.

A. M. Hutson is at The Bat Conservation Trust, London Ecology Centre, 45 Shelton Street, London WC2H 9HJ, UK. 